\title{
Research on Intelligent Management and Application of "Internet + Large-Scale Sports Venues"
}

\author{
Lihong Dong ${ }^{1, a}$, Ma Liang ${ }^{2}$ \\ ${ }^{1}$ Shanghai Second Polytechnic University, Pudong New Area, Shanghai, China \\ ${ }^{2}$ Shanghai Jianqiao University, Pudong New Area, Shanghai, China \\ adlh20082001316@sina.com
}

Keywords: Internet +, large-scale sports venues, wisdom management

\begin{abstract}
Through the literature material method, field survey method, interview method, inductive deductive research method, in view of the current our country large stadiums function mode single, lack of hemopoietic ability, practical problems of the characteristics of the vulgar management, with "Internet $+"$ concept and the emerging technology for traditional stadium intelligent operation integration idea, under the trend of the deep insight into the "Internet + stadium" new connotation, construction of sports venues management wisdom, "Internet + stadium" policy, it is concluded that the wisdom of "Internet + stadium" management application path, Put forward to build special intelligent "race" cloud service system, increase investment in sports stadiums intelligent equipment application system, completes the stadium design link, building a green venues, stadiums and ecological wisdom venues.
\end{abstract}

\section{Introduction}

"Internet + " is a new form of Internet development. It to the Internet architecture, big data for engine, intelligent technology for traditional industry driven depth fusion, and triggered a new round of technological revolution in the traditional industry competition, traditional industry every progress depends on new technology innovation and upgrade of industry. In the "Internet +" new economic mode, as relying on the Internet and Internet of things to build sports cloud, special audience, stadiums, distributed and intelligent products and distributing structure of the intelligent monitoring system, such as large sports venues management application has entered the "+" Internet age. "Internet + stadium" big data management model is the use of advanced technology, communication technology, image acquisition and playback technology, information technology, information management and game central monitoring techniques such as form wisdom sports venues management application system, finally realizes the stadium management information network system, intelligent monitoring system, intelligent system, and application of information systems integration, and fully meet stadium event management services, and after the use and operation, make it play a maximum social benefit and economic benefit. 


\section{2. "Internet + Large-Scale Sports Venues" Intelligent Management Application Theory and}

Policy Analysis

\subsection{New Connotation of "Internet + Large-Scale Sports Venues"}

"Internet $+"$ is a new type of Internet development under innovation 2.0. It is also a new form of economic and social development under the promotion of knowledge society innovation 2.0. ${ }^{[1]}$ pop, "Internet +" is a fruit derived from Internet thinking, main architecture is "Internet + each traditional industry", this kind of fabric is not a simple accumulation, both upgraded version, but two of fusion, taking advantage of the Internet information technology revolution, and all kinds of traditional industry depth fusion and innovation, create new ecological intelligence industry. Similarly, with the popularization of information technology, the stadium industry also actively the nuggets and develop traditional sports venues operating market, through the Internet, big data and cloud computing to improve the application level of comprehensive management of large sports venues.

Large stadiums and gymnasiums serve as the cradle of competitive sports, the base of mass sports and the support of sports industry. The past 30 years, our country the construction of a large number of public sports venues, to meet people's growing material and cultural needs, by differences in size, large sports venues more responsible for the design, planning and construction of world-class competition at home and national the function of the playground. Therefore, what is "large-scale sports venues" and its classification? According to the state sport general administration, ministry of finance issued by the large sports venues open free low charge subsidy funds management method "stipulated in article 5: has been open to the society, low-cost sports department, stadium, namely the audience seats of 20000 or more stadium seats, the audience of 3000 or more stadium seats, the audience of 1500 or more pool (diving); At the same time, according to the standards of sports architecture design standards, the sports venues are mainly divided into four categories. (Table 1) through the above can see, the stadium is a certain scale of the audience seats, can undertake large-scale sports event, and participants for the match, athletes and team officials, referees team, broadcast media, sponsors, audience, security and other groups) to provide supporting services to meet the different needs of public sports venues. As a result, large stadiums and gymnasiums have the comprehensive functions of providing services for large-scale sports events, providing public service products for the audiences and maintaining the value of state-owned assets.

Table 1 Classification standards for sports venues.

\begin{tabular}{|c|c|}
\hline level & Main service requirements \\
\hline Super & Hold the Asian Games, Olympic Games and world class matches \\
\hline Class A & Hold national and international competitions \\
\hline Class B & Hold regional and national individual competitions \\
\hline Class C & Hold local and mass games \\
\hline
\end{tabular}

Data source: the ministry of construction, the state general administration of sports of publishing industry standard of the sports building design specification"

\subsection{Intelligent Management and Construction of Sports Venues}

In the era of "Internet +" hit, stadium is from the traditional operation gradually transformation of resource rent to sports ecological industry operation, the wisdom of this modern management operation mode need to introduce a new generation of information technology, combined with sports venues ontology business combing and core process reengineering, implementation resources online, online services, online management, finally realizes the intelligent management, service and 
wisdom marketing. (Figure 1) the operational advantages of modern intelligent management are mainly reflected in: first, digital means are adopted to promote the refinement of large-scale stadium management and the standardization of service processes. For example, through the digital transformation of sports venues, the orderly storage and centralized control of all information of stadium operation can greatly improve the service level and operation efficiency of sports venues. Second, the Internet technology has broken through the limitation of regional and time in the traditional operation of large-scale sports venues and promoted the development and innovation of sports service products. Make the stadiums and gymnasiums not only a place for customers to consume sports service products, but also a platform for customers' health management and sports socialization. Third, through the third party opening of services and data, it can effectively promote the operation innovation and cross-industry integration of large-scale sports venues. By means of data collection, summary, analysis and mining, not only help the venue operator to clarify management ideas, innovations, and can interact through data and connectivity, boost the depth of the sports industry and other industries. [2]

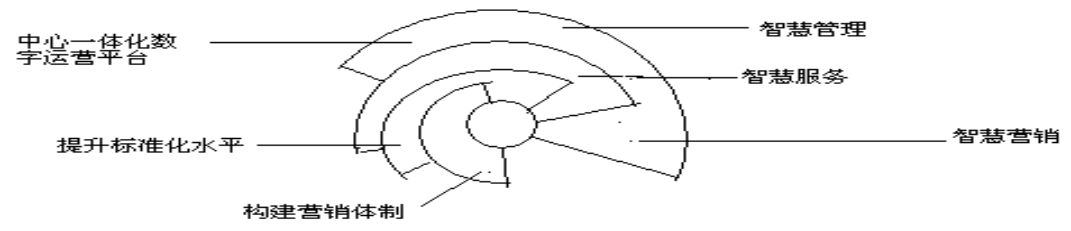

Figure 1 Construction of intelligent management of large stadiums and gymnasiums.

\section{3. "Internet + Large Sports Venues" Policy Analysis}

With the current Internet technology and the related computer networking of big data, the development of mobile communication network technology, iswidely profoundly affects the world's political, economic and social life. Since the gradual commercialization of Internet technology in the mid-1990s, the number of Internet users worldwide reached 16 million in 1996, 100 times the number in 2010. According to statistics, the number of Internet IP addresses in developed countries in Europe, North America, Japan and Oceania exceeded the corresponding population by 2013. In emerging markets, such as developed and developing countries in Asia, the number of IP addresses accounts for about 25 per cent of the population, but the relative number is growing more than twice as fast as in developed countries. [3] in this situation, the software and hardware technology of the Internet, including Internet browsers, website domain name, fiber optic cable communications, etc. There is no doubt already embedded in people, groups and organizations, as well as business, industry and government. To expand on the breadth of Internet technology, therefore, not only in all aspects of the knowledge society, and in the depth of high permeability for political, economic, cultural and business activities of various fields, prompting the dominated by Internet, big data and cloud computing of information revolution and the information society, and make policy makers around the world to rise to the height of the national grand strategy to balance the country's industrial competitiveness. Detailed elaboration to the sports industry field, involves the systematic operating forms of stadium industry in our country, from the 46th article of the state council put forward "the sports industry as a green industry, construct a" sunrise industry, to the sports development much starker choices-and graver consequences-in planning put forward "press ahead with the reform of sports venues management and operation mechanism innovation, introduction and use of modern enterprise system, the venue design, construction, operation management 
integration mode." To 2016, the state council issued the "healthy China 2030" planning outline proposed "overall construction of the national fitness public facilities, strengthening fitness trails, ride the doers of the word, the national fitness center, sports park, community multi-purpose stadium facilities such as construction." In order to further improve the public service system of national fitness, we will make public sports facilities including large sports venues seek a more scientific and systematic management and operation model.

\section{3. "Internet + Large Sports Venues" Intelligent Management Application Path Assumption}

\subsection{Build a Special Intelligent "Competition Cloud" Service System}

In the intelligent management and application mode of Internet + large-scale sports venues, the key to solve this problem is to build a specialized and intelligent competition cloud service system. The so-called competition cloud refers to a big data management platform for sports events and related businesses based on the Internet and the Internet of things. It mainly includes three branch platforms: (1) intelligent management platforms related to sports organization competition and training. (2) data broadcast platform of sports events. (3) the intelligent brain of the timer scoring device. (Figure 2)

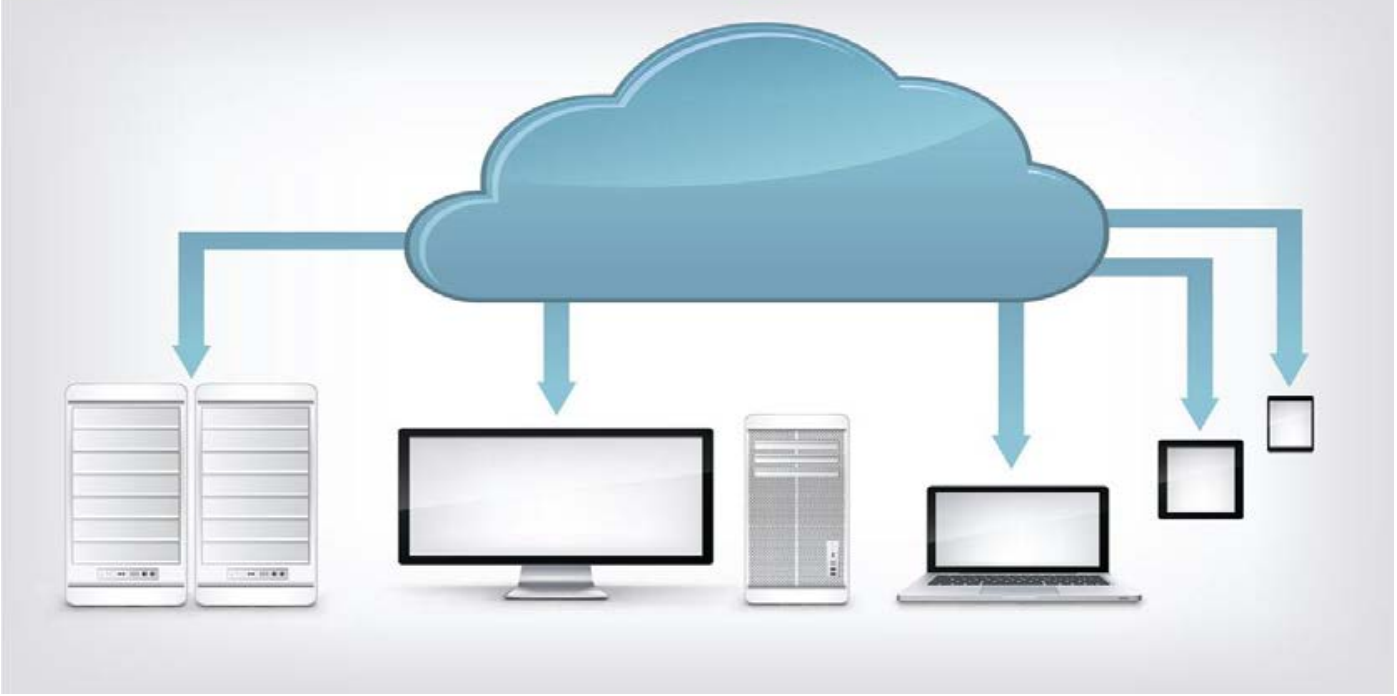

Figure 2 The idea of cloud construction in large stadium and gymnasium intelligence competition.

Cloud on the service object of the competition, mainly covers the medium in the field of school students and TiXie, all levels of sports and sports association, sports club competitions at all levels, all kinds of sports events organization and operating mechanism, etc.; In terms of access mode of competition cloud, it includes institution access, competition access, venue access, equipment access and system access. (as shown in Table 2) on the operating interface, Windows dedicated client, WEB site, android mobile APP, apple mobile APP and other operating interfaces are provided to meet the needs of various user groups. Focus to domestic famous large-scale sports event service Xing Ao company as an example, since 2018, Xing Ao company successively for China national games, the peasant games, the games, Asian games, the Olympic Games, paralympic games, the special Olympics and other major events, comprehensive And the international swimming federation synchronized swimming championships, the southeast Asia games and so on many high level result provide timing score and processing services, its Xing Ao cloud service model better interpretation of "Internet + stadium" wisdom management application advantages. [4] 
Table 2 Cloud access mode of large stadium intelligent competition.

\begin{tabular}{|c|c|}
\hline Access mode & Access to the content \\
\hline $\begin{array}{l}\text { Institutional } \\
\text { access }\end{array}$ & $\begin{array}{l}\text { Sports associations or sports bureaus at all levels, student sp } \\
\text { levels, sports schools at all levels, training bases at all levels } \\
\text { oriented to the functions of management platform and co }\end{array}$ \\
\hline Even & $\begin{array}{r}\text { All levels of comprehensive sports organizati } \\
\text { organizations, various types of individual e } \\
\text { functions of the gam }\end{array}$ \\
\hline $\begin{array}{r}\text { Acce } \\
\mathrm{vt}\end{array}$ & $\begin{array}{r}\text { The access of sports venues is } n \\
\text { partners, and for fun }\end{array}$ \\
\hline $\begin{array}{r}\text { Equi } \\
\text { ac }\end{array}$ & $\begin{array}{l}\text { The timing scoring device is directly connected, and the device is authorized to } \\
\text { access through the open interface to control the completion of all the competition } \\
\text { processes }\end{array}$ \\
\hline Syste & $\begin{array}{l}\text { For the existing on-site score processing system or time scoring system, access is } \\
\text { authorized through the open interface, and the entry registration and result } \\
\text { information are published immediately on the basis of the platform. }\end{array}$ \\
\hline
\end{tabular}

\subsection{Increase Investment in Application System of Intelligent Equipment in Stadium and Gymnasium}

The application system of intelligent equipment of large-scale sports venues includes the application of intelligent building system and the special intelligent products of standard allocation of sports venues. In terms of the present domestic most of the large sports venues, because building library target short-sighted and utilitarian, predominantly sports center stadium construction planning, single function, causes the traditional stadium building intelligent level is low. Therefore, in the "Internet +" concept and the emerging technology for traditional stadium intelligent operation integration idea, under the trend of relying on the Internet of things mode in reducing cost, transmission, the channel, the information management advantages, should increase the special intelligent products of large sports venues, such as improving stadium race function, site conditions, sports lighting, time scoring, broadcast audio, television, network coverage, audience and media services, and so on. Take, for example, the timing scoring equipment at large stadiums. Stadium timing scoring equipment including: track and field/swimming/diving,waterpolo/swimming/ball/gym/ski/bicycle, automatic fare collection system, the flag-raising control system, standard clock system, image acquisition and playback system, facility operation management system, information publishing system, information management system for sporting events, athletes registration management system, the central control system, etc. The system classification is divided into 8 categories. [4]

\subsection{Do a Good Job in the Design of Large Sports Venues, Build Green Venues, Smart Venues and Ecological Venues}

It is an inevitable trend to explore the integrated operation mode of investment, construction and operation of public sports venues in the future. In the current research on how to break the simplification of large sports venues construction mode, the important part is to do a good job of the second design of large sports venues, both indoor and outdoor venues, steel structure, curtain wall, the botanical garden, the floor lighting, fire protection etc are must carry on the design and construction of sports venues dedicated. At the same time, a research resource platform for sports architecture was established to carry out menu selection, select high-quality enterprises with 
experience in designing and construction of large-scale sports venues, and realize integrated solutions. In addition, the stadium large energy consumption in China, the problem of the high cost of operation and maintenance, in the stadium, on the basis of high quality high standard quadratic programming construction to actively promote green construction, adopt green building technology, the construction of the sustainable development of green stadium; We will improve the extensive economic model and build smart and ecological stadiums under the intensive stadium model.

\section{Conclusion}

(1) In an age of "Internet +" hit, stadium is from the traditional operation gradually transformation of resource rent to sports ecological industry operations, modern intelligent management operational advantage is mainly reflected in: one is the refinement of digital management of large sports venues and the standardization of service process. Second, the Internet technology has broken through the limitation of regional and time in the traditional operation of large-scale sports venues and promoted the development and innovation of sports service products. Third, through the third party opening of services and data, it can effectively promote the operation innovation and cross-industry integration of large-scale sports venues.

(2) Vision of smart management application path of "Internet + large sports venues" : build a special intelligent "competition cloud" service system; Increase the investment in the application system of intelligent equipment in sports venues; We will do a good job in the design of large stadiums and build green, smart and ecological stadiums.

\section{Acknowledgements}

The research work described in this paper is supported by 2017 Central financial support project (B5YC150005P4).

\section{References}

[1] "Internet + "activates more information energy. China Internet of things, 2015-7-9

http://www.taizhou.com.cn/old/2011-01/18/content_15425.htm

[2] Wang, J. (2017) Exploration on the operation of sports venues under the new normal. Shanghai: China sports venues association.

[3] Lu, L. (2014) Development of Internet, big data and cloud technology and American economy. International relations research, (4).

[4] Beijing Xingao technology co, LTD. Promotion of xingao innovation project. Shanghai: China sports venue association, 2017. 